\title{
Effects of Radiopaque Double Antibiotic Pastes on the Proliferation, Alkaline Phosphatase Activity and Mineral Deposition of Dental Pulp Stem Cells
}

Jennifer L. Wu, DDS*1; Patrick W. McIntyre, DDS*1. Jung Min Hong, Ph.D*, Ghaeth H. Yassen BDS, MSD, PhD ${ }^{\ddagger}$; Angela Bruzzaniti, PhD*.

*Department of Biomedical Sciences \& Comprehensive Care, Indiana University School of Dentistry, 1121 W Michigan St, Indianapolis, IN 46202, USA.

Current address: Department of Endodontics, Case Western Reserve School of Dental Medicine, 2124 Cornell Rd, Cleveland, OH 44106, USA.

${ }^{1}$ These authors contributed equally to this work

Corresponding authors:

Angela Bruzzaniti

Department of Biomedical Sciences \& Comprehensive Care

Indiana University School of Dentistry

1121 W. Michigan Street

Indianapolis, IN, 46228

Tel: $+1-317-278-3742$

E-mail address: abruzzan@iu.edu

Ghaeth H. Yassen

Department of Endodontics

Case Western Reserve School of Dental Medicine

2124 Cornell Rd.

Cleveland, $\mathrm{OH} 44106$

Tel: $+1-317-437-2240$

E-mail address: ghy4@case.edu

This is the author's manuscript of the article published in final edited form as:

Wu, J. L., McIntyre, P. W., Hong, J. M., Yassen, G. H., \& Bruzzaniti, A. (2020). Effects of radiopaque double antibiotic pastes on the proliferation, alkaline phosphatase activity and mineral deposition of dental pulp stem cells. Archives of Oral Biology, 117, 104764. https://doi.org/10.1016/j.archoralbio.2020.104764 


\section{Keywords}

barium sulfate, zirconium oxide, dental pulp stem cells, double antibiotic paste, mineral deposition, alkaline phosphatase 


\begin{abstract}

\section{Objective}

The aim of this study was to investigate the effects of two radiopaque agents, barium sulfate $\left(\mathrm{BaSO}_{4}\right)$ or zirconium oxide $\left(\mathrm{ZrO}_{2}\right)$ in double antibiotic paste (DAP), on the proliferation and mineral deposition of human dental pulp stem cells (DPSCs).
\end{abstract}

\title{
Materials and methods
}

Radiopaque antimicrobial medicaments composed of methylcellulose (MC) thickening polymer with $\mathrm{BaSO}_{4}$ or $\mathrm{ZrO}_{2}$ and either 1 or $5 \mathrm{mg} / \mathrm{mL}$ DAP (equal portions of metronidazole and ciprofloxacin) were used to investigate DPSC proliferation after 3 days, and alkaline phosphatase (ALP) activity and mineral deposition after 7 and 14 days. Radiopaque agents without DAP and $\mathrm{Ca}(\mathrm{OH})_{2}$ were used as controls.

\section{Results}

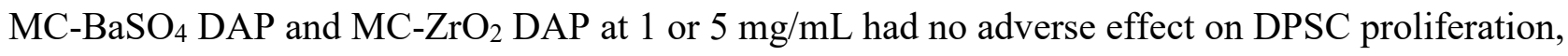
compared to the media and $\mathrm{MC}$ controls. $\mathrm{MC}-\mathrm{ZrO}_{2}$ (DAP-free) greatly increased ALP activity after 7 days. DPSC mineral deposition was modestly reduced at 7 days by $\mathrm{MC}-\mathrm{BaSO}_{4} \mathrm{DAP}$ and $\mathrm{MC}-\mathrm{ZrO}_{2}$ DAP, but not by DAP-free radiopaque agents, and was most reduced by $5 \mathrm{mg} / \mathrm{mL}$ DAP in the 14-day cultures.

\section{Conclusions}

MC-BaSO 4 or $\mathrm{MC}-\mathrm{ZrO}_{2}$ medicaments containing up to $5 \mathrm{mg} / \mathrm{mL}$ of DAP supported the proliferation and early osteogenic differentiation of DPSCs. Low DAP concentrations and short culture times led to more favorable effects on ALP activity and mineral deposition by DPSCs. The findings suggest that radiopaque agents added for the purpose of detecting whether medicaments occupy the full extent of the root canal may have clinical applications. Radiopaque antibiotic medicaments containing low DAP concentrations may be an alternative to $\mathrm{Ca}(\mathrm{OH})_{2}$ for regenerative endodontic procedures. 


\section{Introduction}

Root canal disinfection during regenerative endodontic procedures (REP) is an essential step to achieve successful clinical outcomes. However, disinfection during REP poses multiple challenges in comparison to disinfection during non-surgical root canal treatment. The minimal or no use of mechanical root canal preparation in REP makes it harder to disrupt the intra-radicular biofilm and reduce the microbial load. Furthermore, immature teeth have been suggested to contain more resistant biofilms in comparison to biofilms from mature teeth (Cvek, Nord, \& Hollender, 1976; Jacobs et al., 2017). In the majority of failed REP cases, signs and/or symptoms of persistent infection have been reported (Chaniotis, 2017; Liu \& Xu, 2018; Zizka, Buchta, Voborna, Harvan, \& Sedy, 2016). Recent in vivo reports have demonstrated a significant association between residual bacteria and the lack of periapical osseous healing during REP (P. Verma et al., 2017). Furthermore, the residual bacterial biofilms and their byproducts have been found to modify the osteogenic differentiation of stem cells from apical papillae (SCAP) (Vishwanat et al., 2017).

The current clinical recommendation of American Association of Endodontists (AAE) suggest the use of calcium hydroxide $\left(\mathrm{Ca}(\mathrm{OH})_{2}\right)$ or $1-5 \mathrm{mg} / \mathrm{mL}$ of antibiotic combinations as an intracanal medicament (AAE, 2018). This recommendation is based on multiple in vitro studies suggesting that higher concentrations of antibiotic combinations are cytotoxic to dental pulp stem cells (DPSCs) (Chuensombat, Khemaleelakul, Chattipakorn, \& Srisuwan, 2013) and SCAP (Ruparel, Teixeira, Ferraz, \& Diogenes, 2012). Recent antibacterial studies have demonstrated that $1-5 \mathrm{mg} / \mathrm{mL}$ of triple antibiotic paste (TAP) (Arruda et al., 2018) or double antibiotic paste (DAP) (Jenks, Ehrlich, Spolnik, Gregory, \& Yassen, 2016; McIntyre et al., 2019) have superior antimicrobial properties than $\mathrm{Ca}(\mathrm{OH})_{2}$. However, the clinical application of low concentration of antibiotic into the root canal is challenging and inconsistent. There is a need to tailor an intracanal medicament for REP that exhibits superior antimicrobial properties with minimal cytotoxicity to stem cells. In a recent in vitro study injectable low concentrations of DAP containing the radiopaques, barium sulfate $\left(\mathrm{BaSO}_{4}\right)$ or zirconium oxide $\left(\mathrm{ZrO}_{2}\right)$, were found to have superior residual antimicrobial properties in comparison to $\mathrm{Ca}(\mathrm{OH})_{2}(\mathrm{R}$. Verma, Fischer, Gregory, \& Yassen, 2018). However, the effect of these radiopaque medicaments on osteogenesis has not been investigated. The aim of the current study was to investigate the effects of MC plus DAP pastes containing the radiopaques, $\mathrm{BaSO}_{4}$ or $\mathrm{ZrO}_{2}$, on the proliferation, differentiation and mineral deposition of DPSCs in vitro. 


\section{Materials and methods}

\subsection{Preparation of radiopaque DAP in methylcellulose}

Two radiopaque materials, $\mathrm{BaSO}_{4}$ and $\mathrm{ZrO}_{2}$, were independently used in the current study. DAP (1 $\mathrm{mg} / \mathrm{mL}$ and $5 \mathrm{mg} / \mathrm{mL}$ ) containing either $\mathrm{BaSO}_{4}$ or $\mathrm{ZrO}_{2}$, were prepared as described in a recent study (R. Verma et al., 2018). Briefly, 10 and $50 \mathrm{mg}$ of equal parts of ciprofloxacin and metronidazole (Champs Pharmacy, San Antonio, TX) were dissolved separately in $10 \mathrm{~mL}$ sterile water to form 1 and $5 \mathrm{mg} / \mathrm{mL}$ DAP solutions, respectively. Thereafter, $3 \mathrm{~g}$ of $\mathrm{BaSO}_{4}$ (Reagent Plus; Sigma-Aldrich, St

Louis, MO) or $\mathrm{ZrO}_{2}$ (5 mm powder, Sigma-Aldrich) was gradually incorporated into each DAP solution under controlled continuous stirring to form a DAP slurry composed of $30 \%$ (w/v) of each radiopaque material. Then, $0.7 \mathrm{~g}$ methylcellulose powder (MC) (Methocel $60 \mathrm{HG}$, Sigma-Aldrich) was gradually dissolved into each DAP slurry to create a paste, which was then centrifuged (7000 rpm for 15 minutes), resulting in homogenous injectable pastes containing either 1 or $5 \mathrm{mg} / \mathrm{mL}$ DAP plus $\mathrm{BaSO}_{4}$ or $\mathrm{ZrO}_{2}$. DAP-free $\mathrm{MC}$ control pastes with $\mathrm{BaSO}_{4}$ or $\mathrm{ZrO}_{2}$ were also prepared using a similar protocol. In addition, $\mathrm{MC}$ paste without a radiopaque agent or DAP was prepared and tested as an independent control group. All pastes were prepared and used under sterile conditions in a biohazard cell culture hood at room temperature. A radiopaque $\mathrm{Ca}(\mathrm{OH})_{2}$ intracanal medicament (UltraCal XS; Ultradent, South Jordan, UT) was used as a commercial control group throughout all experiments in this study. The experimental groups used in the study are as follows.

Group 1: Media (negative) control

Group 2: $\mathrm{MC} ; \mathrm{BaSO}_{4}$

Group 3: $\mathrm{MC} ; \mathrm{BaSO}_{4} ; \mathrm{DAP} 1 \mathrm{mg} / \mathrm{ml}$

Group 4: $\mathrm{MC}$; $\mathrm{BaSO}_{4}$; DAP $5 \mathrm{mg} / \mathrm{ml}$

Group 5: $\mathrm{MC} ; \mathrm{ZrO}_{2}$

Group 6: $\mathrm{MC} ; \mathrm{ZrO}_{2}$; DAP $1 \mathrm{mg} / \mathrm{ml}$

Group 7: $\mathrm{MC} ; \mathrm{ZrO}_{2}$; DAP 5 mg/ml

Group 8: $\mathrm{Ca}(\mathrm{OH})_{2}$

\subsection{DPSC culture conditions}

Human DPSCs were purchased from ALLCells (Alameda, CA, USA), passaged once and aliquots stored in liquid nitrogen. For each experiment, DPSCs were thawed and seeded into $10-\mathrm{cm}^{2}$ dishes and cultured in $\alpha$-MEM (HyClone Laboratories Inc., South Logan, UT, USA) with 10\% heat-inactivated FBS (Biowest, Kansas city, MO, USA) and 1\% penicillin/streptomycin (Lonza, Allendale, NJ, USA). 
Sub-confluent cultures between passages 3 and 5 were seeded into 24-well plates (Alkali Scientific Inc.). The seeding density was optimized for the different assays and is indicated in the following sections. The following day, transwell chamber inserts consisting of semi-permeable $1.0 \mu \mathrm{m}$ pore membrane (Corning, NY, USA) were added to the culture plates as reservoirs for each of the medicaments. $100 \mu \mathrm{L}$ of each of the medicaments were added to the transwell chambers followed by $750 \mu \mathrm{L}$ of culture media. DPSCs in the bottom chamber received $500 \mu \mathrm{L}$ of fresh culture media, resulting in a final media volume of $1.35 \mathrm{~mL} /$ well. The culture media was replaced every 2-3 days. Experimental plates were incubated at $37^{\circ} \mathrm{C}$ in a $95 \% \mathrm{CO}_{2} / 5 \% \mathrm{O}_{2}$ incubator for the duration of each experiment.

\subsection{Proliferation assay}

DPSCs $\left(2 \times 10^{4}\right.$ cells/well) were cultured as described above with each of the medicaments placed in transwell chambers above the cell monolayers. After 3 days, the transwells containing medicaments were removed and cell monolayers were washed once with phosphate buffered saline (PBS) and assayed for $3 \mathrm{~h}$ using the CellTiter 96 Aqueous Non-Radioactive Cell Proliferation Assay kit (MTS) (Promega, \#G5421). The assay is based on conversion of a tetrazolium compound [3-(4,5dimethylthiazol-2-yl)-5-(3-carboxymethoxyphenyl)-2-(4-sulfophenyl)-2H-tetrazolium, inner salt; MTS] and phenazine methosulfate (PMS), an electron coupling reagent, into a formazan product by

dehydrogenase enzymes found in metabolically active cells. The quantity of formazan product, which is measured at $490 \mathrm{~nm}$, is directly proportional to the number of living cells in the culture wells.

\subsection{Alkaline phosphatase activity assay}

DPSCs were plated at $4 \times 10^{4}$ cells/well in 24-well plates, and cultured with the medicaments for 7 days in growth media supplemented with $5 \mathrm{mM} \beta$-glycerolphosphate and $50 \mu \mathrm{M}$ ascorbic acid to induce osteogenic differentiation. After 7 days, the medicaments were removed, and the cells were washed, lysed and then assayed for alkaline phosphatase (ALP) activity using a quantitative biochemical assay as previously reported (Posritong et al., 2018). Alternatively, after 7 days with the medicaments, the transwells were removed and the cells were cultured in osteogenic media (without medicaments) for an additional 7 days (14 day total culture duration). For ALP activity determination, the cells were lysed in mRIPA buffer consisting of $50 \mathrm{mM}$ Tris-Cl pH 7.5, $150 \mathrm{mM} \mathrm{NaCl,} \mathrm{1 \%} \mathrm{NP-40,}$ $0.25 \%$ sodium deoxycholate and supplemented with $10 \mu \mathrm{g} / \mathrm{mL}$ leupeptin hydrochloride, $10 \mu \mathrm{g} / \mathrm{mL}$ aprotinin, $10 \mu \mathrm{g} / \mathrm{mL}$ pepstatin, $1 \mathrm{mM}$ PMSF, $1 \mathrm{mM}$ sodium fluoride, and $1 \mathrm{mM}$ sodium orthovanadate. 
The cell lysates were sonicated for 5 minutes, and then centrifuged at 13,000 rpm for 5 minutes and the supernatant collected. 1-5 $\mu \mathrm{L}$ of the lysate was assayed in triplicate and added to the ALP substrate containing $2 \mathrm{mg} / \mathrm{mL}$ p-nitrophenyl phosphate (Sigma-Aldrich) in 1.5 M alkaline buffer (SigmaAldrich), and then the mixture was incubated for $1 \mathrm{~h}$ at $37^{\circ} \mathrm{C}$ in the dark. The enzymatic reaction was stopped by adding $20 \mathrm{mM} \mathrm{NaOH}$ to the mixture (200 $\mu \mathrm{L}$ final volume) and the absorbance at $405 \mathrm{~nm}$ was recorded. An ALP standard curve was calculated concurrent with the assays using serial dilutions of 4-nitrophenol and $20 \mathrm{mM} \mathrm{NaOH}$ and used to determine total ALP activity. Total ALP activity per sample was normalized for total protein content in the well, using the Pierce ${ }^{\mathrm{TM}}$ BCA protein assay kit (Thermo Scientific) following the manufacturer's specifications.

\subsection{Alkaline phosphatase cell staining}

ALP staining was performed as previously reported (Eleniste et al., 2016). Briefly, DPSCs were fixed in $10 \%$ formalin for $10 \mathrm{~min}$, and washed twice with PBS. The ALP staining solution was prepared by dissolving $1 \mathrm{mg}$ Naphthol AS=MX (Sigma) in one droplet of N,N-dimethylformamide (Wako, Osaka, Japan) and resuspended in $10 \mathrm{ml}$ of $0.1 \mathrm{M}$ Tris- $\mathrm{HCl}$ buffer containing $2 \mathrm{mM} \mathrm{MgCl}$., after which $6 \mu \mathrm{g}$ of Fast BB salt (Sigma) was added. The cells were stained for $20 \mathrm{~min}$ at $37^{\circ} \mathrm{C}$, then washed with tap water several times, and stored dry. The cells were imaged under an inverted microscope (Leica DMI 4000B, Leica Microsystems).

\subsection{Mineral deposition assay}

Quantitative analysis of mineral deposition was performed as previously described (Posritong et al., 2018) using the calcium-binding stain, Alizarin Red-S. Briefly, DPSCs were plated at 4 x $10^{4}$ cells/well and cultured in osteogenic media containing ascorbic acid and $\beta$-glycerolphosphate, with the medicaments placed in the transwell chambers. After 7 days, the transwell chambers were discarded and the cells washed with PBS and fixed in 3.7\% formaldehyde in PBS for 15 min (HyClone Laboratories, Inc.), followed by a 15 min wash with PBS. For extended culture durations, the medicaments were removed after 7 days, and the cells were cultured for an additional 7 days in osteogenic media (without medicaments) (14 days total culture duration), and then fixed with 3.7\% formaldehyde as described above. For quantitative mineral deposition assay, the PBS was aspirated and $500 \mu \mathrm{L}$ of $40 \mathrm{mM}$ Alizarin Red-S Solution pH 4.2 (Sigma-Aldrich) was added to each group and set on a shaker for 30 minutes. The wells were subsequently washed 5 times with tap water to remove excess stain. After washing, $500 \mu \mathrm{L}$ of 1\% (w/v) cetylpyridinium chloride (CPC) (Sigma \#C0732) was 
used to extract extracellularly bound Alizarin Red-S stain. 1\% CPC and $40 \mathrm{mM}$ Alizarin Red-S was used to create a serially diluted standard curve. The calcium concentration was determined using a standard curve and was based on the known ability of Alizarin to bind 2 mol of calcium per mol of dye. All samples were read in triplicate on the spectrophotometer at $562 \mathrm{~nm}$, as previously reported (Stanford, Jacobson, Eanes, Lembke, \& Midura, 1995). Mineral deposits were stained and imaged as previously reported (Posritong et al., 2018). Briefly, after staining with Alizarin Red-S as described above, the wells were washed several times with distilled water, and then directly imaged under an inverted microscope (Leica DMI 4000B, Leica microsystems). Representative images are shown.

\subsection{Statistical analyses}

Three independent experiments were conducted for each assay, and assays were performed in triplicate or quadruplicate. Groups were compared for differences in proliferation, ALP activity, and mineral deposition (nodule formation) using one-way ANOVA that included a fixed effect for group and a random effect for trial, followed by pair-wise tests between groups. Tukey Adjustment for Multiple Comparisons was used to adjust between multiple experiments. A 5\% significance level was used for all tests. All results shown represent the mean \pm standard error of the mean (SEM) for the combined data sets. Statistical significance between groups is indicated by different letters above respective bars in graphs $(\mathrm{p}<0.05)$.

\section{Results}

\subsection{Effect of medicaments on the proliferation of DPSCs}

DPSC proliferation was not affected by $\mathrm{BaSO}_{4}$ and $\mathrm{ZrO}_{2}$ added to the $1 \mathrm{mg} / \mathrm{mL}$ DAP or $5 \mathrm{mg} / \mathrm{mL}$ DAP pastes, and results were similar to the effects seen for the media, DAP-free paste, and the $\mathrm{Ca}(\mathrm{OH})_{2}$ controls. The data suggest that the addition of the radiopaques alone or in combination with $1 \mathrm{mg} / \mathrm{mL}$ DAP or $5 \mathrm{mg} / \mathrm{mL}$ DAP pastes had no adverse effect on the proliferation and cytotoxicity of DPSCs $(\mathrm{p}<$ 0.05) (Figure 1).

\subsection{Effects of medicaments on ALP activity of DPSCs}

For the 7-day time point, only the DAP-free $\mathrm{MC}-\mathrm{ZrO}_{2}$ paste induced a significant increase in ALP activity in comparisons to all other pastes $(\mathrm{p}<0.01)$, were were similar to each other (Figure 2$)$. The $\mathrm{BaSO}_{4} \mathrm{DAP}$ and $\mathrm{ZrO}_{2}$ DAP at 1 and $5 \mathrm{mg} / \mathrm{mL}$ did not demonstrate a significant change in ALP activity 
in comparison to the media or MC controls. Moreover, the $\mathrm{Ca}(\mathrm{OH})_{2}$ group did not show a relative difference in ALP activity compared to any other group in the 7-day cultures.

We also extended the culture duration for an additional 7 days (14 days total) after removal of the medicaments to examine the residual effects on DPSCs. Figure 3 shows that the stimulatory effect of DAP-free $\mathrm{MC}-\mathrm{ZrO}_{2}$ paste that was observed in 7 day cultures (Figure 2) was absent after 14 days. DAP-free $\mathrm{MC}-\mathrm{ZrO}_{2}$ paste showed a similar level of ALP activity as all other radiopaque groups, except the MC- $\mathrm{ZrO}_{2}$ DAP5 group. The MC-ZrO 2 DAP5 group showed a small but significant decrease in ALP activity, compared to media control, DAP-free $\mathrm{MC}-\mathrm{BaSO}_{4}, \mathrm{DAP}$-free $\mathrm{MC}^{-} \mathrm{ZrO}_{2}$ and $\mathrm{MC}-\mathrm{ZrO}_{2}$ DAP1 groups. Lastly, the $\mathrm{Ca}(\mathrm{OH})_{2}$ group showed higher ALP activity than the DAP-free MC-BaSO 4, DAP-free MC-BaSO 4 and $\mathrm{MC}-\mathrm{ZrO}_{2}$ DAP5 medicaments.

\subsection{Effects of medicaments on the mineral deposition capacity of DPSCs}

For the 7-day time point, the media control, MC paste, DAP-free $\mathrm{MC}-\mathrm{BaSO}_{4}$ paste, DAP-free MC$\mathrm{ZrO}_{2}$ paste and $\mathrm{Ca}(\mathrm{OH})_{2}$ all exerted a similar effect on mineral deposition by DPSCs (Figure 4).

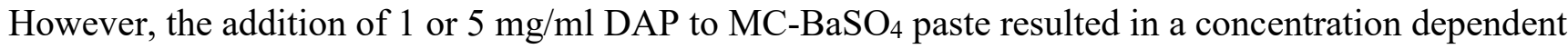
decrease in mineral deposition compared to media, $\mathrm{MC}$ paste and $\mathrm{Ca}(\mathrm{OH})_{2}$ control groups. Similarly, $\mathrm{MC}-\mathrm{ZrO}_{2} \mathrm{DAP}$ at 1 and $5 \mathrm{mg} / \mathrm{mL}$ groups showed a significant decrease in mineral deposition compared to all other controls: media, MC paste, DAP-free $\mathrm{MC}-\mathrm{BaSO}_{4}$ paste, DAP-free $\mathrm{MC}-\mathrm{ZrO}_{2}$ and $\mathrm{Ca}(\mathrm{OH})_{2}(\mathrm{p}<0.01)$.

For the 14-day time point, a similar concentration dependent decrease in mineral deposition was observed with the $\mathrm{MC}_{-\mathrm{BaSO}_{4}} \mathrm{DAP}$ and $\mathrm{MC}-\mathrm{ZrO}_{2} \mathrm{DAP}$ at 1 and $5 \mathrm{mg} / \mathrm{mL}$ pastes. Similar to the 7-day cultures, the DAP-containing groups were lower than the $\mathrm{Ca}(\mathrm{OH})_{2}$ controls. However, the radiopaques alone (DAP-free) showed no decrease in mineral deposition compared to the media control, MC

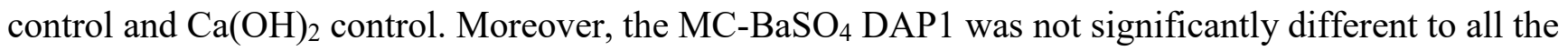
control groups.

\section{Discussion}

Numerous studies explored the biocompatibility of stem cells against various intracanal antibiotic medicaments and suggested the use of low concentrations of antibiotics to minimize their cytotoxic effects (Althumairy, Teixeira, \& Diogenes, 2014; Chuensombat et al., 2013; Phumpatrakom \& 
Srisuwan, 2014; Ruparel et al., 2012). However, these published studies explored pure antibiotic pastes mixed with water at higher concentrations, or used diluted antibiotic solutions. Pure antibiotic pastes and diluted solutions of antibiotics present multiple clinical challenges as they cannot be easily handled or consistently delivered. In addition, they lack the ability to be traced radiographically once they are administered within the root canal system. The biological effects of methylcellulose-based DAP have been considerably explored in a recent published study (McIntyre et al., 2019). However, no previous studies have explored the biological effects of incorporating radiopaque components into an antibioticbased intracanal medicament tailored for REP. Therefore, the goal of the current study was to investigate the proliferation and mineral deposition capabilities of DPSCs cultured with radiopaque antimicrobial methylcellulose pastes containing low concentration of metronidazole and ciprofloxacin (DAP). The proliferation and mineral deposition potential of the radiopaque pastes, in antibiotic-free conditions was also investigated in an attempt to provide a clearer understanding of the biological effects of methylcellulose and radiopaque agents.

The current study demonstrated that both $\mathrm{MC}_{-} \mathrm{BaSO}_{4} \mathrm{DAP}$ and $\mathrm{MC}-\mathrm{ZrO}_{2} \mathrm{DAP}$ at 1 and $5 \mathrm{mg} / \mathrm{mL}$ did not have harmful effects on the proliferation of DPSCs. Indeed, these medicaments showed no apparent cytotoxic effects on the DPSCs as all data were similar to the media control, MC paste, DAPfree $\mathrm{MC}-\mathrm{BaSO}_{4}$ paste, and DAP-free $\mathrm{MC}-\mathrm{ZrO}_{2}$ paste. Furthermore, both $\mathrm{MC}-\mathrm{BaSO}_{4} \mathrm{DAP}$ and $\mathrm{MC}-$ $\mathrm{ZrO}_{2}$ DAP at 1 and $5 \mathrm{mg} / \mathrm{mL}$ behaved similarly to the $\mathrm{Ca}(\mathrm{OH})_{2}$ group, which is the gold-standard used clinically for endodontic regeneration. Previous studies with a relatively similar experimental design have demonstrated that $1 \mathrm{mg} / \mathrm{mL}$ of antibiotic solution caused significant cytotoxicity to DPSCs and SCAP ranging from 0-50\% (Chuensombat et al., 2013; Phumpatrakom \& Srisuwan, 2014; Ruparel et al., 2012). The non-cytotoxic nature of 1 and $5 \mathrm{mg} / \mathrm{mL}$ of radiopaque DAP reported in the current study could be explained by the presence of MC in combination with the radiopaque agents. In support of this, previous studies have shown that methylcellulose (McIntyre et al., 2019), $\mathrm{ZrO}_{2}$ (Gomes Cornelio et al., 2011) and $\mathrm{BaSO}_{4}$ (Pascon \& Spangberg, 1990) did not show deleterious biological effects. Our current study also confirms the non-cytotoxic behavior of DAP-free pastes containing radiopaque agents as well as DAP-free methylcellulose paste without radiopaque agents. It is worth noting that in a recent publication, it was reported that $5-10 \mathrm{mg} / \mathrm{mL}$ of radiopaque DAP (R. Verma et al., 2018) and non-radiopaque DAP (Jenks et al., 2016; McIntyre et al., 2019) have superior antimicrobial properties compared to $\mathrm{Ca}(\mathrm{OH})_{2}$ against single-, dual- and multi-species biofilms. Additionally, the current AAE guidelines recommend the use of up to $5 \mathrm{mg} / \mathrm{mL}$ of antibiotic mixtures, or $\mathrm{Ca}(\mathrm{OH})_{2}$, as intracanal medicaments during REP (AAE, 2018). 


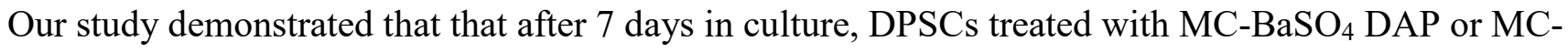
$\mathrm{ZrO}_{2} \mathrm{DAP}$ at 1 and $5 \mathrm{mg} / \mathrm{mL}$ showed a similar effect on an ALP activity, which is a marker of osteogenic differentiation and maturation of DPSCs. However, DAP-free MC-ZrO 2 paste showed superior effects on ALP activity compared to all other groups, which is in line with our recent study (McIntyre et al., 2019). Further, it was reported that the addition of $\mathrm{ZrO}_{2}$ to Biodentine increased its radiopacity and did not appear to change its physicochemical and biological properties (Ochoa-

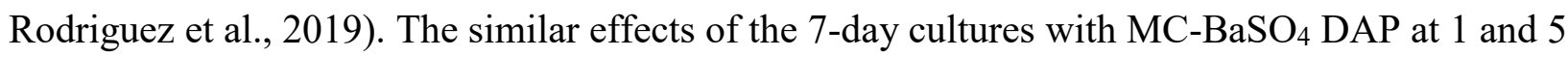
$\mathrm{mg} / \mathrm{mL}$ or $\mathrm{MC}-\mathrm{ZrO}_{2} \mathrm{DAP} 1 \mathrm{mg} / \mathrm{mL}$ group, compared to the media, $\mathrm{MC}$ and $\mathrm{Ca}(\mathrm{OH})_{2}$ groups are in contrast to previous results suggesting that methylcellulose hydrogels containing $1-10 \mathrm{mg} / \mathrm{mL}$ of DAP caused gradual and significant reduction in ALP activity and mineral deposition (McIntyre et al., 2019). Only the MC-ZrO 2 DAP $1 \mathrm{mg} / \mathrm{mL}$ group showed an inhibitory effect and only in 14-day cultures. Further, the previous study suggested that the use of diluted TAP as low as $0.39 \mu \mathrm{g} / \mathrm{mL}$ caused a significant reduction in ALP activity and mineralized nodule formation after 7 days (Phumpatrakom \& Srisuwan, 2014). Importantly, in comparison with previous studies, our new findings suggest the addition of the radiopaque agents to $\mathrm{MC}+\mathrm{DAP}$ provide a favorable environment for DPSC growth and early differentiation as indicated in our ALP results.

The $\mathrm{MC}-\mathrm{BaSO}_{4} \mathrm{DAP}$ or $\mathrm{MC}-\mathrm{ZrO}_{2} \mathrm{DAP}$ at 1 and $5 \mathrm{mg} / \mathrm{mL}$ caused a modest concentration-dependent decrease in DPSC mineralized nodule formation in both the 7 day and 14 day cultures. However, the

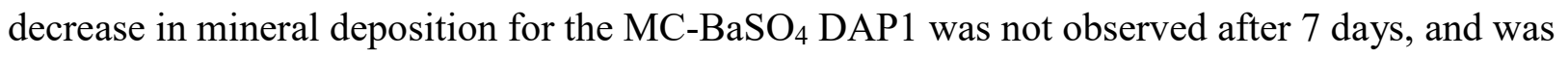
modest after 14 days. Overall, results between $\mathrm{MC}-\mathrm{BaSO}_{4} \mathrm{DAP}$ and $\mathrm{MC}-\mathrm{ZrO}_{2} \mathrm{DAP}$ pastes were similar. In comparison to a previous study which also used lower antibiotic concentration (Phumpatrakom \& Srisuwan, 2014), our findings also showed that higher concentrations of antibiotics, as well as extended exposure time, could lead to a reduction in mineral deposition, even though initial osteogenic differentiation (as evidenced in our ALP assay) were not affected. Whether or not extending the culture times further (without medicaments) will allow mineral deposition to return to normal remains to be determined.

Collectively, this study is in support of multiple other studies suggesting the concentration-dependent adverse biological effects of DAP (McIntyre et al., 2019; Ruparel et al., 2012). However, it appears that the addition of methylcellulose and radiopaque agents may minimize and slow down the toxic effects of the antibiotics, especially if exposure times are limited. This can be specifically important 
within the context of REP since the intracanal medicaments are only applied for a relatively short period of time from as little as 1 week and up to 4 weeks (AAE, 2018).

In the current study, $\mathrm{Ca}(\mathrm{OH})_{2}$ did not cause any negative effects on proliferation, ALP activity and mineral deposition of DPSCs, which generally agrees with previous studies (Chen et al., 2016; McIntyre et al., 2019; Ruparel et al., 2012). It is worth noting that pure $\mathrm{Ca}(\mathrm{OH})_{2}$ was previously found to be cytotoxic to dental pulp cells (Kobayashi et al., 2013; Labban, Yassen, Windsor, \& Platt, 2014). The commercial $\mathrm{Ca}(\mathrm{OH})_{2}$ formula tested in this study (UltraCal) contains $\mathrm{MC}$ and $\mathrm{BaSO}_{4}$ as the stabilizing polymer and radiopaque agent, respectively, which is similar to our medicament, and which may improve the biocompatibility of $\mathrm{Ca}(\mathrm{OH})_{2}$ as an intracanal medicament. The use of the $\mathrm{Ca}(\mathrm{OH})_{2}$ as an intracanal medicament during REP is a logical option since it is readily available, easily used and relatively non-cytotoxic. Nevertheless, the use of $\mathrm{Ca}(\mathrm{OH})_{2}$ as an intracanal medicament during REP was associated with significantly higher intracanal calcification, in comparison to the use of antibiotic medicaments (Song et al., 2017). Furthermore, only osteoid-like tissues were found after the use of $\mathrm{Ca}(\mathrm{OH})_{2}$ during REP (Austah et al., 2018). On the other hand, both osteoid-like and dentin-like hard tissue were observed after the use of DAP during REP (Austah et al., 2018). Thus, a DAP-based medicament containing a radiopaque agent may offer better clinical outcomes. Future investigations are warranted to explore the type of mineralized hard tissue formed after REP in teeth disinfected with various intracanal medicaments.

We examined the effect of several radiopaque medicaments on DPSCs, rather than stem cells from the apical papilla (SCAP). Both types of stem cells have demonstrated positive stem cells markers such as STRO-1, CD146 and CD34 (Bakopoulou et al., 2011a, 2011b). Furthermore, both types of stem cells were proposed to display an active potential for proliferation and mineralization (Abuarqoub, Awidi, \& Abuharfeil, 2015; Bakopoulou et al., 2011a, 2011b).

In conclusion, this study indicates that intracanal medicaments containing $\mathrm{MC}$ plus $\mathrm{BaSO}_{4}$ or $\mathrm{ZrO}_{2}$ in combination with up to $5 \mathrm{mg} / \mathrm{mL}$ of DAP were not cytotoxic and did not inhibit DPSC proliferation. Furthermore, it appears that the active antibiotic components in these radiopaque medicaments may cause a concentration-dependent reduction in mineral nodule formation. As is the case with all drugs, the lowest effective concentration that achieves the desired clinical outcome is recommended. Thus, low concentrations of DAP in combination with radiopaque solutions, as well as short duration times, 
may lead to beneficial outcomes in biocompatibility and mineral nodule formation, as well as antimicrobial activity.

\section{Funding}

These studies were funded by the Indiana University School of Dentistry.

\section{Conflict of Interest}

The authors declare that they have no conflict of interest.

\section{Ethical approval.}

All procedures performed in studies involving human teeth were in accordance with the ethical standards of the institutional and/or national research committee and with the 1964 Helsinki declaration and its later amendments or comparable ethical standards.

\section{Informed consent.}

Deidentified human dental pulp stem cells were purchased commercially under an approved Institutional Review Board protocol. 


\section{References}

AAE, American Association of Endodontists. (2018). AAE Clinical Considerations for a Regenerative Procedure.

Available at: https://www.aae.org/specialty/wpcontent/uploads/sites/2/2018/06/ConsiderationsForRegEndo AsOfApril2018.pdf.

Abuarqoub, D., Awidi, A., \& Abuharfeil, N. (2015). Comparison of osteo/odontogenic differentiation of human adult dental pulp stem cells and stem cells from apical papilla in the presence of platelet lysate. Arch Oral Biol, 60(10), 1545-1553.

Althumairy, R. I., Teixeira, F. B., \& Diogenes, A. (2014). Effect of dentin conditioning with intracanal medicaments on survival of stem cells of apical papilla. J Endod, 40(4), 521-525.

Arruda, M. E. F., Neves, M. A. S., Diogenes, A., Mdala, I., Guilherme, B. P. S., Siqueira, J. F., Jr., \& Rocas, I. N. (2018). Infection Control in Teeth with Apical Periodontitis Using a Triple Antibiotic Solution or Calcium Hydroxide with Chlorhexidine: A Randomized Clinical Trial. J Endod, 44(10), 1474-1479.

Austah, O., Joon, R., Fath, W. M., Chrepa, V., Diogenes, A., Ezeldeen, M., . . Ruparel, N. B. (2018). Comprehensive Characterization of 2 Immature Teeth Treated with Regenerative Endodontic Procedures. J Endod, 44(12), 1802-1811.

Bakopoulou, A., Leyhausen, G., Volk, J., Tsiftsoglou, A., Garefis, P., Koidis, P., \& Geurtsen, W. (2011a). Assessment of the impact of two different isolation methods on the osteo/odontogenic differentiation potential of human dental stem cells derived from deciduous teeth. Calcif Tissue Int, 88(2), 130-141.

Bakopoulou, A., Leyhausen, G., Volk, J., Tsiftsoglou, A., Garefis, P., Koidis, P., \& Geurtsen, W. (2011b). Comparative analysis of in vitro osteo/odontogenic differentiation potential of human dental pulp stem cells (DPSCs) and stem cells from the apical papilla (SCAP). Arch Oral Biol, 56(7), 709-721.

Chaniotis, A. (2017). Treatment Options for Failing Regenerative Endodontic Procedures: Report of 3 Cases. J Endod, 43(9), 1472-1478.

Chen, L., Zheng, L., Jiang, J., Gui, J., Zhang, L., Huang, Y., . . Fan, Y. (2016). Calcium Hydroxide-induced Proliferation, Migration, Osteogenic Differentiation, and Mineralization via the Mitogen-activated Protein Kinase Pathway in Human Dental Pulp Stem Cells. J Endod, 42(9), 1355-1361.

Chuensombat, S., Khemaleelakul, S., Chattipakorn, S., \& Srisuwan, T. (2013). Cytotoxic effects and antibacterial efficacy of a 3-antibiotic combination: an in vitro study. J Endod, 39(6), 813-819.

Cvek, M., Nord, C. E., \& Hollender, L. (1976). Antimicrobial effect of root canal debridement in teeth with immature root. A clinical and microbiologic study. Odontol Revy, 27(1), 1-10.

Eleniste, P. P., Patel, V., Posritong, S., Zero, O., Largura, H., Cheng, Y. H., . . Bruzzaniti, A. (2016). Pyk2 and Megakaryocytes Regulate Osteoblast Differentiation and Migration Via Distinct and Overlapping Mechanisms. J Cell Biochem, 117(6), 1396-1406. 
Gomes Cornelio, A. L., Salles, L. P., Campos da Paz, M., Cirelli, J. A., Guerreiro-Tanomaru, J. M., \& Tanomaru Filho, M. (2011). Cytotoxicity of Portland cement with different radiopacifying agents: a cell death study. J Endod, 37(2), 203-210.

Jacobs, J. C., Troxel, A., Ehrlich, Y., Spolnik, K., Bringas, J. S., Gregory, R. L., \& Yassen, G. H. (2017). Antibacterial Effects of Antimicrobials Used in Regenerative Endodontics against Biofilm Bacteria Obtained from Mature and Immature Teeth with Necrotic Pulps. J Endod, 43(4), 575-579.

Jenks, D. B., Ehrlich, Y., Spolnik, K., Gregory, R. L., \& Yassen, G. H. (2016). Residual antibiofilm effects of various concentrations of double antibiotic paste used during regenerative endodontics after different application times. Arch Oral Biol, 70, 88-93.

Kobayashi, M., Tsutsui, T. W., Kobayashi, T., Ohno, M., Higo, Y., Inaba, T., \& Tsutsui, T. (2013). Sensitivity of human dental pulp cells to eighteen chemical agents used for endodontic treatments in dentistry. Odontology, 101(1), 43-51.

Labban, N., Yassen, G. H., Windsor, L. J., \& Platt, J. A. (2014). The direct cytotoxic effects of medicaments used in endodontic regeneration on human dental pulp cells. Dent Traumatol, 30(6), 429-434.

Liu, X., \& Xu, X. (2018). MicroRNA-137 dysregulation predisposes to osteoporotic fracture by impeding ALP activity and expression via suppression of leucine-rich repeat-containing G-protein-coupled receptor 4 expression. Int J Mol Med, 42(2), 1026-1033.

McIntyre, P. W., Wu, J. L., Kolte, R., Zhang, R., Gregory, R. L., Bruzzaniti, A., \& Yassen, G. H. (2019). The antimicrobial properties, cytotoxicity, and differentiation potential of double antibiotic intracanal medicaments loaded into hydrogel system. Clin Oral Investig, 23(3), 1051-1059.

Ochoa-Rodriguez, V. M., Tanomaru-Filho, M., Rodrigues, E. M., Guerreiro-Tanomaru, J. M., Spin-Neto, R., \& Faria, G. (2019). Addition of zirconium oxide to Biodentine increases radiopacity and does not alter its physicochemical and biological properties. J Appl Oral Sci, 27, e20180429.

Pascon, E. A., \& Spangberg, L. S. (1990). In vitro cytotoxicity of root canal filling materials: 1. Gutta-percha. J Endod, 16(9), 429-433.

Phumpatrakom, P., \& Srisuwan, T. (2014). Regenerative capacity of human dental pulp and apical papilla cells after treatment with a 3-antibiotic mixture. J Endod, 40(3), 399-405.

Posritong, S., Hong, J. M., Eleniste, P. P., Mclntyre, P. W., Wu, J. L., Himes, E. R., . . Bruzzaniti, A. (2018). Pyk2 deficiency potentiates osteoblast differentiation and mineralizing activity in response to estrogen or raloxifene. Mol Cell Endocrinol, 474, 35-47.

Ruparel, N. B., Teixeira, F. B., Ferraz, C. C., \& Diogenes, A. (2012). Direct effect of intracanal medicaments on survival of stem cells of the apical papilla. J Endod, 38(10), 1372-1375. 
Song, B., Zhang, Y. L., Chen, L. J., Zhou, T., Huang, W. K., Zhou, X., \& Shao, L. Q. (2017). The role of Toll-like receptors in periodontitis. Oral Dis, 23(2), 168-180.

Stanford, C. M., Jacobson, P. A., Eanes, E. D., Lembke, L. A., \& Midura, R. J. (1995). Rapidly forming apatitic mineral in an osteoblastic cell line (UMR 106-01 BSP). J Biol Chem, 270(16), 9420-9428.

Verma, P., Nosrat, A., Kim, J. R., Price, J. B., Wang, P., Bair, E., . . Fouad, A. F. (2017). Effect of Residual Bacteria on the Outcome of Pulp Regeneration In Vivo. J Dent Res, 96(1), 100-106.

Verma, R., Fischer, B. I., Gregory, R. L., \& Yassen, G. H. (2018). The Radiopacity and Antimicrobial Properties of Different Radiopaque Double Antibiotic Pastes Used in Regenerative Endodontics. J Endod, 44(9), 1376-1380.

Vishwanat, L., Duong, R., Takimoto, K., Phillips, L., Espitia, C. O., Diogenes, A., . . Ruparel, N. B. (2017). Effect of Bacterial Biofilm on the Osteogenic Differentiation of Stem Cells of Apical Papilla. J Endod, 43(6), 916-922.

Zizka, R., Buchta, T., Voborna, I., Harvan, L., \& Sedy, J. (2016). Root Maturation in Teeth Treated by Unsuccessful Revitalization: 2 Case Reports. J Endod, 42(5), 724-729. 
Fig 1. Proliferation assays performed on DPSCs treated with $\mathrm{MC}$ containing $\mathrm{BaSO}_{4}$ or $\mathrm{ZrO}_{2}$ plus various concentrations of DAP ( 1 and $5 \mathrm{mg} / \mathrm{mL}$ ), compared to either DAP-free $\mathrm{BaSO}_{4}$, DAP-free $\mathrm{ZrO}_{2}$, methylcellulose paste (MC) only, or the untreated media control. Cells were cultured with the medicaments for 3 days then assayed using the MTS proliferation assay kit. Results showed there were no significant differences between any of the experimental groups ( $p>0.05)$. The mean $\pm \mathrm{SE}$ is shown.

Fig 2. ALP activity assays of DPSCs after 7 days. DPSCs were cultured for 7 days with various concentrations of MC-BaSO 4 DAP (1 and $5 \mathrm{mg} / \mathrm{mL}$ ), MC- $\mathrm{ZrO}_{2}$ DAP (1 and $5 \mathrm{mg} / \mathrm{mL}$ ), DAP-free MC$\mathrm{BaSO}_{4}$ paste, DAP-free $\mathrm{MC}-\mathrm{ZrO}_{2}$ paste, methylcellulose (MC) control, and the untreated media control. Cells were cultured in osteogenic media for 7 days. Only the DAP-free $\mathrm{MC}^{-\mathrm{ZrO}_{2}}$ group showed a statistical significant increase in ALP activity compared to all other treatment groups $(p<0.01)$. ALP activity was similar for all other groups $(p>0.05)$. The mean $\pm S E$ is shown.

Fig 3. ALP activity assays of DPSCs after 14 days. DPSCs were cultured with various concentrations of $\mathrm{MC}-\mathrm{BaSO}_{4}$ DAP (1 and $5 \mathrm{mg} / \mathrm{mL}$ ), $\mathrm{MC}-\mathrm{ZrO}_{2}$ DAP (1 and $5 \mathrm{mg} / \mathrm{mL}$ ), DAP-free MC$\mathrm{BaSO}_{4}$ paste, DAP-free $\mathrm{MC}-\mathrm{ZrO}_{2}$ paste or controls. Cells were cultured with the medicaments in osteogenic media for 7 days, after which the medicaments were removed and the cells cultured for an additional 7 days in osteogenic media (14 days total culture time) before being assayed. A) Cells were assayed for ALP enzymatic activity. The mean $\pm \mathrm{SE}$ is shown. Statistically significant comparisons are indicated by letters above bar graphs $(\mathrm{p}<0.05$. B) DPSCs were also stained for ALP and representative images are shown. Scale bar indicates $100 \mu \mathrm{m}$.

Fig 4. Mineral deposition of DPSCs after 7 days. Mineral deposition by DPSCs treated for 7 days with various concentrations of $\mathrm{MC}^{-B_{a S O}}$ DAP (1 and $5 \mathrm{mg} / \mathrm{mL}$ ), $\mathrm{MC}-\mathrm{ZrO}_{2}$ DAP (1 and $5 \mathrm{mg} / \mathrm{mL}$ ), DAP-free MC-BaSO4 paste, DAP-free $\mathrm{MC}-\mathrm{ZrO}_{2}$ paste and controls. Cells were cultured with the medicaments in osteogenic media for 7 days, then assayed for mineral deposition. The mean $\pm \mathrm{SE}$ is shown. Statistically significant comparisons $(\mathrm{p}<0.01)$ between individual groups is indicated by the lower-case letters above each bar as indicated in the legend.

Fig 5. Mineral deposition of DPSCs after 14 days. DPSCs were cultured with the following medicament groups; $\mathrm{MC}_{-\mathrm{BaSO}_{4}} \mathrm{DAP}$ (1 and $5 \mathrm{mg} / \mathrm{mL}$ ), $\mathrm{ZrO}_{2} \mathrm{MC}-\mathrm{DAP}$ (1 and $5 \mathrm{mg} / \mathrm{mL}$ ), DAP-free MC-BaSO4 paste, DAP-free $\mathrm{MC}-\mathrm{ZrO}_{2}$ paste, and controls. Cells were cultured with the medicaments 
in osteogenic media for 7 days, after which the medicaments were removed and the cells cultured for an additional 7 days in osteogenic media (14 days total culture time). A) Cells were assayed for mineral deposition. The mean $\pm \mathrm{SE}$ is shown. Statistically significant comparisons $(\mathrm{p}<0.05)$ between individual groups is indicated by the lower-case letters above each bar as indicated in the legend. B) DPSCs were stained for mineral deposits and representative images are shown. Scale bar indicates 100 $\mu \mathrm{m}$. 


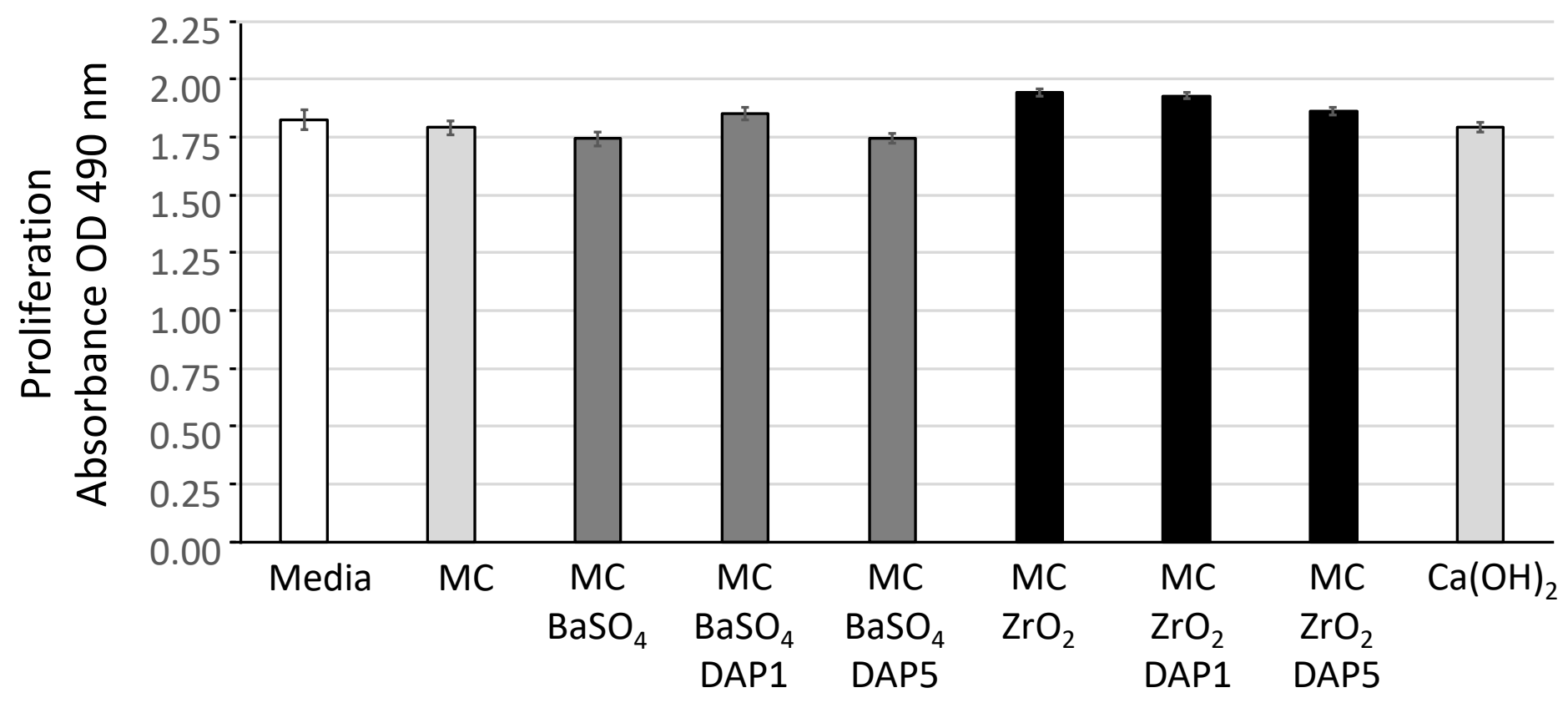




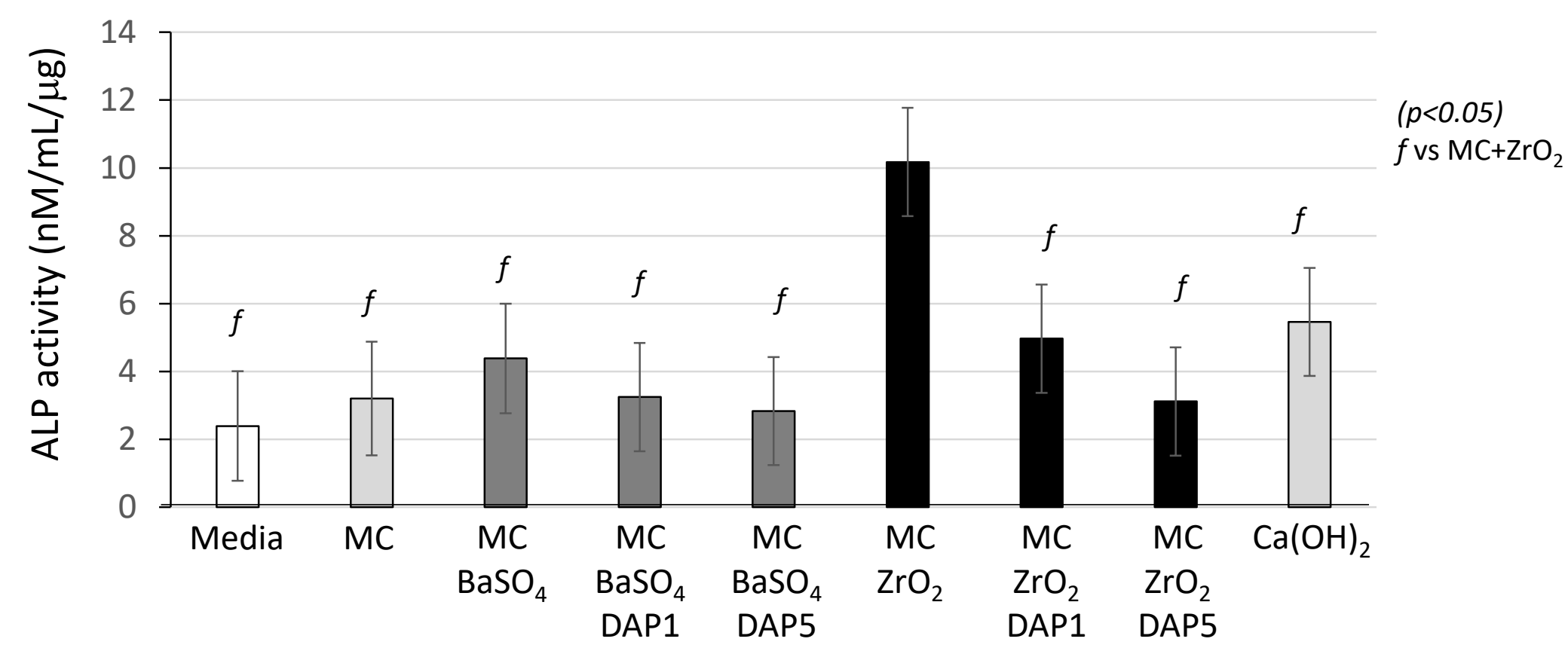


A

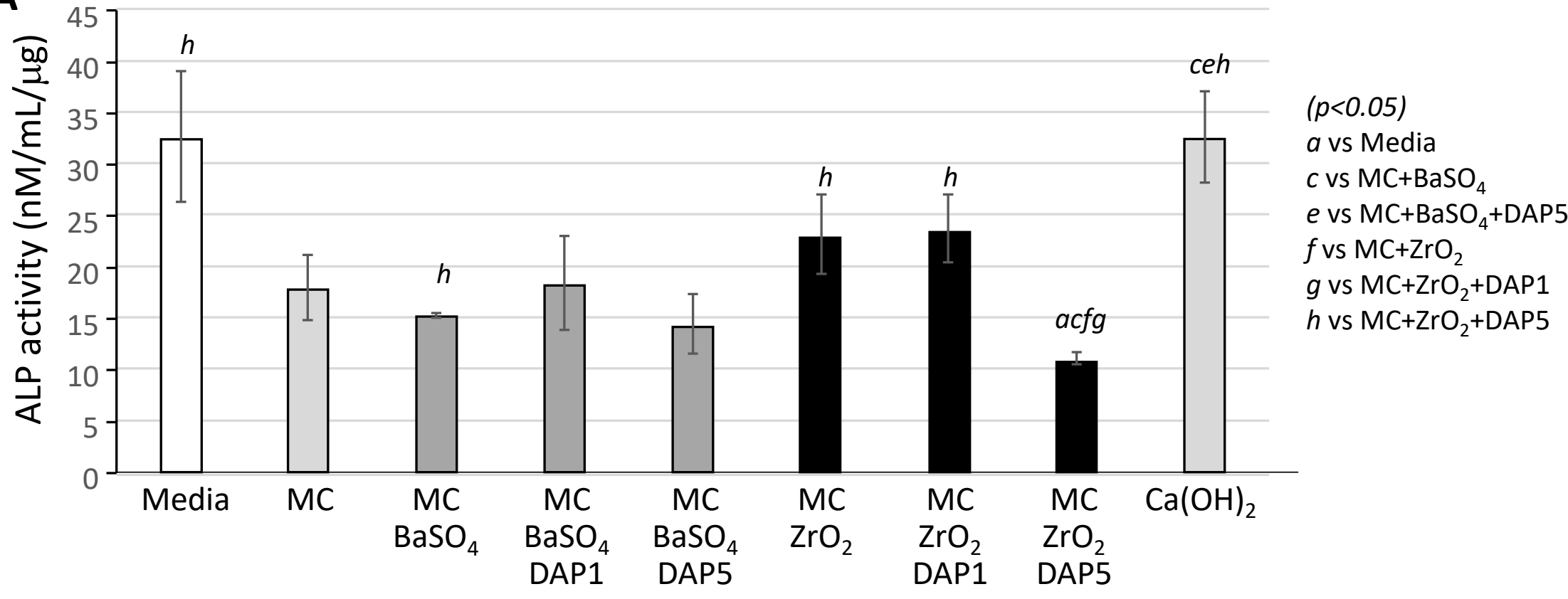

B

Media

$\mathrm{MC}$

$\mathrm{MC}_{-} \mathrm{BaSO}_{4}$

$\mathrm{MC}^{-\mathrm{BaSO}_{4} \mathrm{DAP1}}$

$\mathrm{MC}-\mathrm{BaSO}_{4} \mathrm{DAP5}$

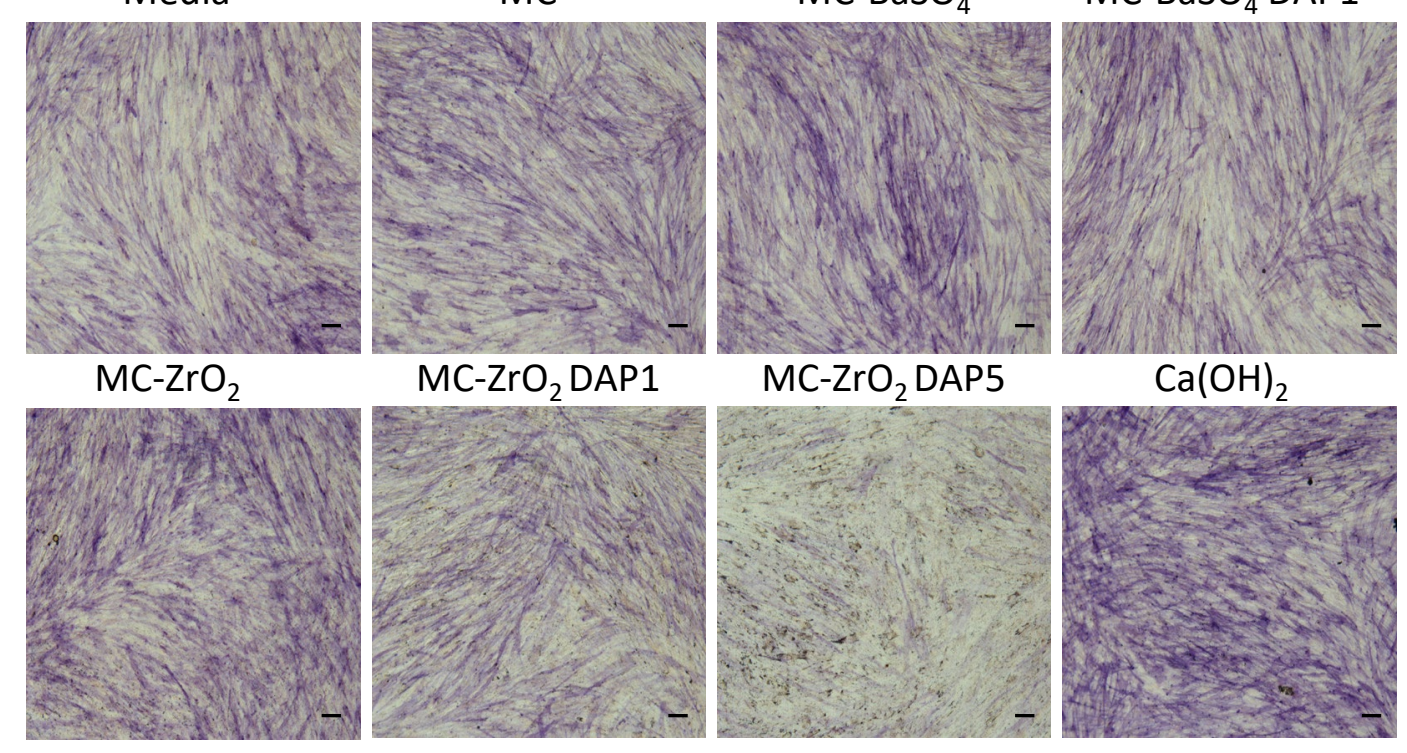




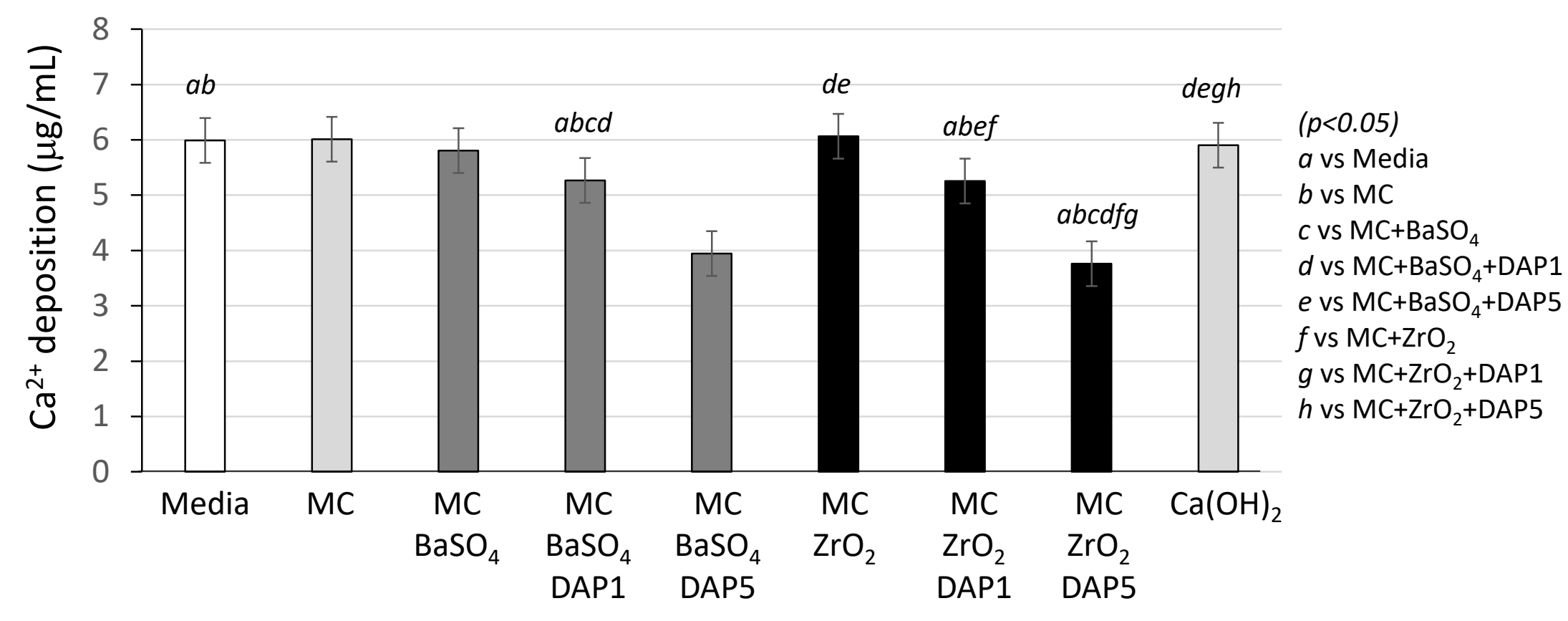




\section{A}

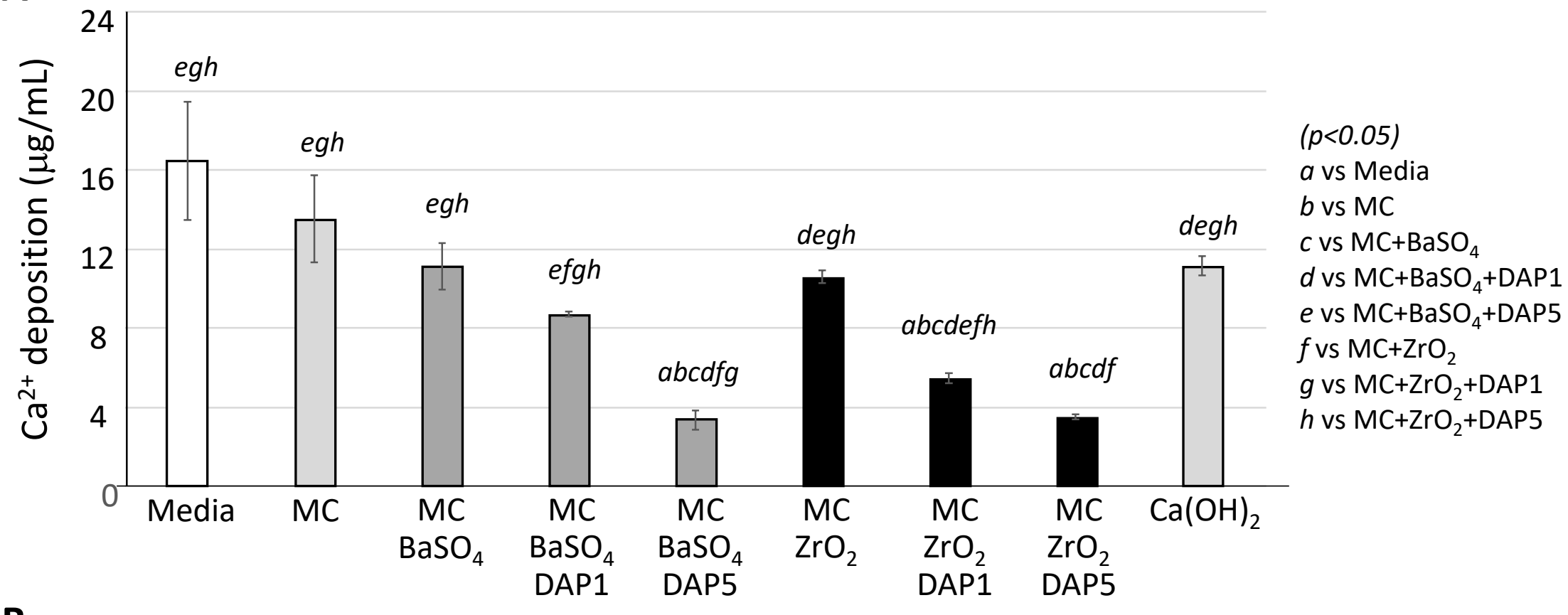

B

Media

MC

$\mathrm{MC}-\mathrm{BaSO}_{4}$

$\mathrm{MC}-\mathrm{BaSO}_{4} \mathrm{DAP} 1 \quad \mathrm{MC}-\mathrm{BaSO}_{4} \mathrm{DAP} 5$

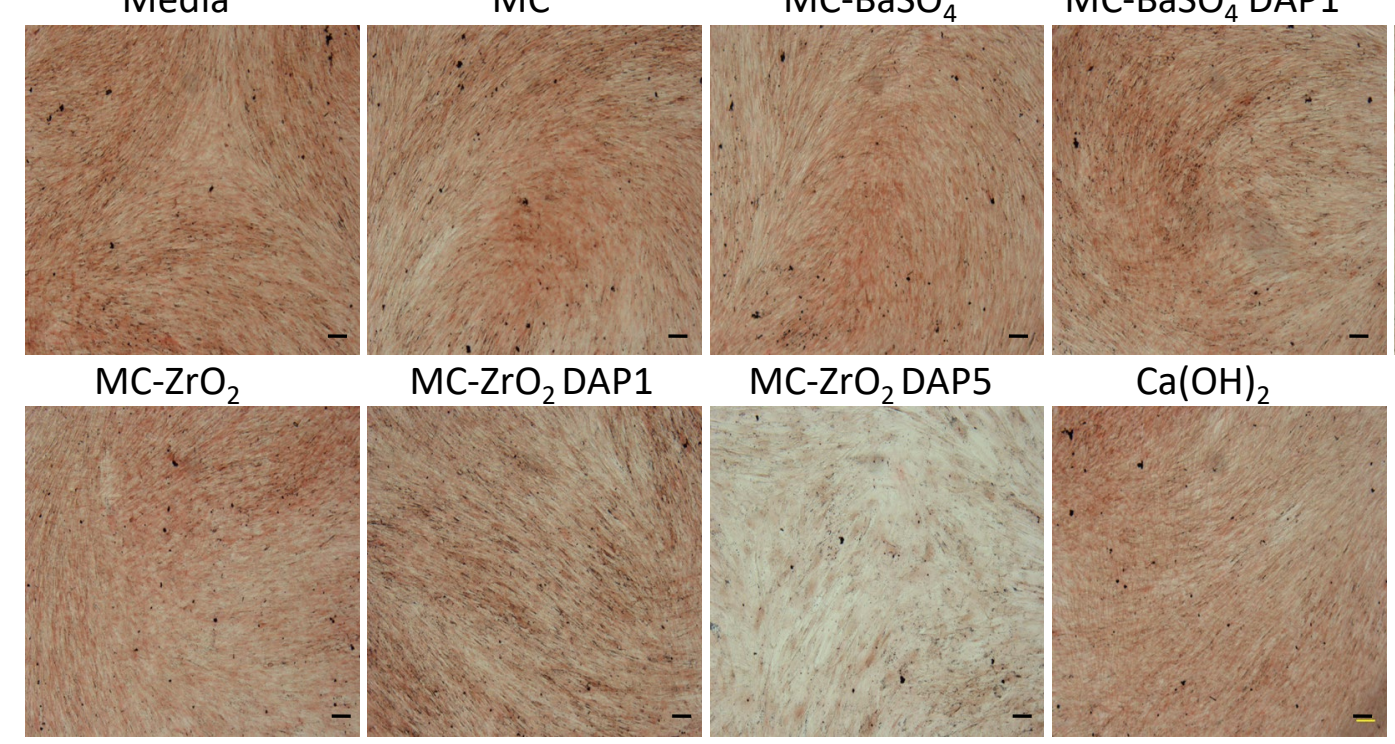

